\title{
The Construction of Power Cloud Integrated with Heterogeneous Application Service Systems
}

\author{
Ling Zheng and Jiangang Yao \\ College of Electrical and Information Engineering, Hunan University, Changsha 410082, China
}

\begin{abstract}
As the smart grid develops rapidly in China, modern power system has been turning into an information system with massive and heterogeneous data. In this paper, the integration of heterogeneous service software and internet-of-things application platforms has been proposed to build private cloud for power system (referred to power cloud).The basic concepts of cloud computing and the key technologies are introduced initially. Then it focuses on the construction mechanism of power cloud, which includes cloud computing data center, virtual desktop, and the combination of cloud applications with internet-of-things application service systems. In the end, the overall structure design of power cloud integrated with heterogeneous application service systems is carried out. It shows that the power cloud has strong advantages over traditional application systems. The construction of power cloud is of great significance to the future development of China's power grid.
\end{abstract}

Keywords-power system; cloud computing; cloud architecture; structure design

\section{INTRODUCTION}

With the development of modern electric power system and the overall construction of smart grid in China, all kinds of information collection devices and intelligent systems have been widely used in power systems leading to a sharp increase in the data of power enterprise. At present, power system is facing the following problems during the process of intelligent construction and development: 1) All kinds of systems and automation equipment have collected a large amount of power data, but they are independent with each other and lack effective information interaction, which causes the problems that the data resources are repetitive, the integration degree of information is low and the data compatibility is bad, etc. [1] 2) With the continuous development of information technology, the costs of infrastructure management and energy consumption are increasing, and the maintenance and upgrade of all kinds of intelligent systems are relatively difficult. 3) The modern electric power system has higher requirements for load forecasting, power-flow calculation, short circuit analysis and other electrical calculation. However, the current configuration of the system which has not been able to calculate and store the massive, heterogeneous and multi-state data cannot meet the needs of long-term construction of smart grid. 4) The availability, utilization and security of enterprise information are insufficient; the security, integrity and authenticity of enterprise information and information systems cannot be guaranteed [2]. The power industry is closely related to the national production and individuals' life. All of the above problems will affect intelligent development of China's power system in the future.

Cloud computing is an approach to integrate massive data resources and processor resources from many distributed computers, which has many advantages such as strong computing capability, high availability, on-demand service, dynamic expansion, energy saving, environmental protection, etc.[3]-[5]. From the overall perspective, this paper has studied the applications of cloud computing in power system, including the architecture levels of power enterprise data center, the realization of users' terminal desktop cloud, the construction and interaction of power internet-of-things and cloud application platforms, etc. Building cloud power through the integration of various heterogeneous cloud applications and networking application service systems, power system can achieve the interaction of grid information and the sharing of power resources; Power enterprises can master the real-time operation data of power grid; maintain and update all kinds of intelligent systems in the cloud environment; share all sorts of cloud services, and realize information office as well.

\section{CONCEPTS OF CLOUD COMPUTING}

\section{A. The Meaning of Cloud Computing}

Cloud computing refers to automatic, low-cost, fast and flexible IT services based on the internet to provide users with capabilities of computing, storage, development of platform and software from the scale-oriented resource pool. The software and hardware resources of cloud computing exist in a way of distributed sharing, which can be expanded and configured dynamically, finally supplying to users in the form of service[6]-[7].

\section{B. Key Technologies of Cloud Computing}

\section{1) Virtualization technology}

Virtualization is an abstract method that represents a computer resource. Through virtualization, the representation, access and management of computer resources such as infrastructures, systems, and software can be simplified, and a standard interface for these resources is provided to accept inputs and outputs.

By virtualizing the server, memory and network, the infrastructure layer of cloud computing provides users with dynamic, scalable virtual resources.

In the development process of the desktop cloud, desktop virtualization technology is used to decouple the user's desktop environment from the terminal device, so that users 
can access cloud resources anywhere and anytime through the network.

\section{2) Distributed storage and parallel computing}

Distributed file system is the core of distributed storage system. The physical memory resource of the system management is not necessarily the local node, which can be connected to the node by the computer network [8].

Parallel computing in parallel computers decomposes an application into multiple subtasks, and distributes to different processors mutually coordinating, concurrently executing and fast solving these computational tasks.

Hadoop is a reliable platform for the storage of distributed data and execution of MapReduce-type analysis tasks. It is mainly divided into three layers: the bottom layer is the core of Hadoop which realizes the construction and maintenance of the distributed system; intermediate layer is composed of Hadoop distributed file system HDFS for data storage, distributed parallel computing model MapReduce for meeting the demand of massive data processing, and zoo keeper for implementing the construction and management of distributed system.; the upper layer provides a set of tools for Hadoop, such as distributed database HBase, etc. Hadoop is an effective solution for PaaS layer of cloud computing. Its structure level is shown in Figure I.

\begin{tabular}{|c|l|l|}
\hline \multicolumn{3}{|c|}{ Hadoop tools and apps } \\
\hline HDFS & MapReduce & Zookeeper \\
\hline \multicolumn{3}{|c|}{ Hadoop Core } \\
\hline
\end{tabular}

FIGURE I. THE STRUCTURE LEVEL OF HADOOP PLATFORM.

\section{Cloud Computing Architecture for Power System}

The cloud computing architecture of power system is mainly divided into two parts: management and service.

Cloud management is composed of user layer, system layer and detecting layer, which provides service with user management, billing management, operation management, security management, disaster management and other functions and techniques of management[9]-[11], ensuring that power cloud computing can be carried out safely and stably.

The service layer contains three levels SaaS, PaaS and IaaS. IaaS (Infrastructure-as-a-Service): provide virtualized infrastructure resources, including servers, memory, network, power equipment and other hardware resources, which can be dynamic allocated according to the users' needs. PaaS (Platform-as-a-Service): take the responsibility for the deployment and maintenance of the software running environment and providing API of cloud computing in the infrastructure. The PaaS layer can adopt Hadoop architecture, which builds on the virtual host, to provide data processing, storage, analysis and other intelligent decision-makings for cloud applications of power system. SaaS (Software-as-a-Service): it is a collection of SaaS platforms and cloud applications. Connecting to the network, users can access all kinds of cloud applications through the browser.

\section{Construction Mechanism of Power Cloud}

\section{A. Cloud Computing Data Center of Power Enterprises}

Cloud computing provides underlying resources in the form of data center. Presently, there are many idle computing and storage resources in provincial and regional power-supply companies. Through the virtualization technology, the hardware resources of the companies are shielded, which can make the best use of the existing hardware resources. In the meantime, it can easily maintain and manage the infrastructure layer.

According to the specific circumstances, China's power system can build 2-level data center to achieve 3 -tier applications of corporate headquarter, provincial grid companies, local companies and other electric power enterprises. Power group corporate headquarter sets up the first-level data center, which has a quantity of infrastructures and complex types of equipment and the network. The network environment, types of equipment, physical architecture, etc. of the data center, should be detailedly investigated to determine the parts which are suitable for virtualization. Then deploy and integrate the application clusters organically; Provincial grid companies set up second-level data centers. The cross- cloud interaction between and the headquarter and the company or among the companies can be achieved through dedicated networks; Local grid company and other electric power enterprises interact with the data center of the provincial grid companies through the dedicated network as well. The structure of cloud computing data center of electric power enterprises is shown in Figure II. Cloud architecture established by the group headquarter can be understood as the main cloud of the power cloud; cloud architectures by provincial grid companies, municipal and other power enterprises as sub-clouds; sub-clouds are included in the main cloud, and they share the resources of the entire power cloud.

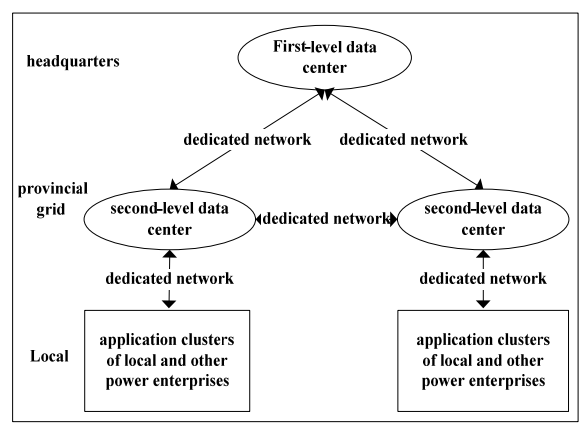

FIGURE II. THE STRUCTURE LEVEL OF DATA CENTER OF ELECTRIC POWER ENTERPRISES.

\section{B. Virtual Desktop Cloud}

Desktop virtualization technology can decouple user's desktop environment from the terminal. It can store and run the user's original desktop environment in the server of the background data center in the form of virtual mirror, while the front end uses PC, notebook, Internet, smart phones, PDA or other small devices connected to the network to access the cross-platform application programs. 
The construction of desktop cloud can realize mobile office for power enterprises. Staff, through the identity authentication and login the mobile terminal, will get their own desktop resources, which greatly improves the working flexibility of power enterprises. If the staff is under the condition of absence, he can also get information on the work site. For instance, the dispatcher can see the operation of the server in the generator room through a mobile phone. When finding something abnormal, the relevant personnel can be notified to deal with it in time to reduce the occurrence of accidents.

Virtual desktop cloud has another advantage: as the desktop environment is saved as a virtual machine, the user can make a snapshot and backup; when the user's desktop environment is attacked or destroyed, he can quickly restore the backup.

\section{The Integration of Applications of Power Cloud and \\ Application Service Systems of Internet-of-Things}

Cloud application is a service which is most closely connected with the power enterprises. Cloud applications can be accessed through the browser, or with an open API, allowing users to access their applications without any configuration as long as there is a browser and the internet is connected, no matter where they are and what kind of terminals they use. Different applications publish external interfaces uniformly on the cloud platforms, and establish unified standards and security mechanisms. On the basis of the cloud architecture discussed in chapter 1.3, cloud application suppliers develop various types of application software for power enterprises to achieve the functions of safety dispatching, transmission monitoring, load forecasting, power-flow calculation, intelligent marketing, enterprise resource management, etc., providing a series of intelligent systems for power generation, transmission, distribution, substation, supplying and dispatching.

The construction of smart grid combines the internet-of-things technology, which offers application functions like data acquisition and control (Application of SCADA system), electric information monitoring, equipment status monitoring and early warning of distribution network (application of DMS ), material allocation and management, etc. Cloud computing is the core of the internet-of-things which faces to smart grid applications. Various power system state sensors collect operation status information from all kinds of equipment of power generation, transmission, distribution and demand side. The real-time and dynamic information is transmitted to the cloud computing data center through the power optical fiber network, power carrier communication network and wireless network, being collected, analyzed and processed.

As a service-oriented architecture, SOA can exert its advantages in system interface and interface standardization. Using sorts of heterogeneous cloud applications and networking applications including existing common software for electric power enterprises such as power generation dispatching platform, load forecasting system, intelligent marketing platform, SCADA system, DMS system, etc., can integrate and build a new software system.
Under the SOA architecture, SaaS application developers can take advantage of the existing various software components and frameworks to realize the mutual communication among applications and facilitate the rapid development and production of new applications. At the same time, users do not need to consider the installation, upgrade and maintenance of the system, which are done by application suppliers in the "cloud".

Cloud computing has the characteristic of fast processing of large-scale data, the resources integrated by which can be shared by all kinds of application service systems. The developing trend of China's power grid will transit from empirical-type to analysis and active type, during which time the timeliness of big data information is particularly important. The combination of cloud application and Internet of things can realize the rapid analysis and risk assessment of power grid, which is of great significance to the safe and stable operation of smart grid.

\section{Structure Design and Service Advantages of POWER CLOUD}

\section{A. Structure Design of Power Cloud}

Power cloud is mainly composed of server clusters of data center, sensors, and other data acquisition equipment, electrical equipment and other hardware resources, the integration of computing resources (including cloud application software and platforms for networking applications, basic parameters of grid, etc.), users' access terminal, firewall and network. Their relationship is shown in Figure III.

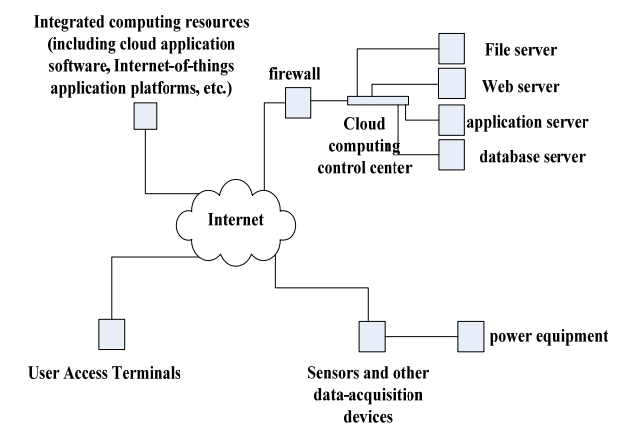

FIGURE III. THE COMPONENTS OF POWER CLOUD

Power enterprises, through desktop cloud, access all types of cloud applications and applications of Internet-of-things technology in power grid to achieve functions like high-performance power-flow calculation, short circuit calculation and other electrical computing, massive data storage, real-time data online analysis, marketing management, information-technology office, etc.; Based on the concept of software as a service, provide a complete set of service-oriented application services to the demands; Uniformed service access interfaces shield the lower-layer distributed computing and infrastructure resources to provide encapsulated platform services for power cloud; Resource managements accomplish tasks of discovery, distribution, storage and scheduling of resources; Data center provides infrastructure resources of power cloud. Thus, the overall 
structure of power cloud is formed, as shown in Figure IV.

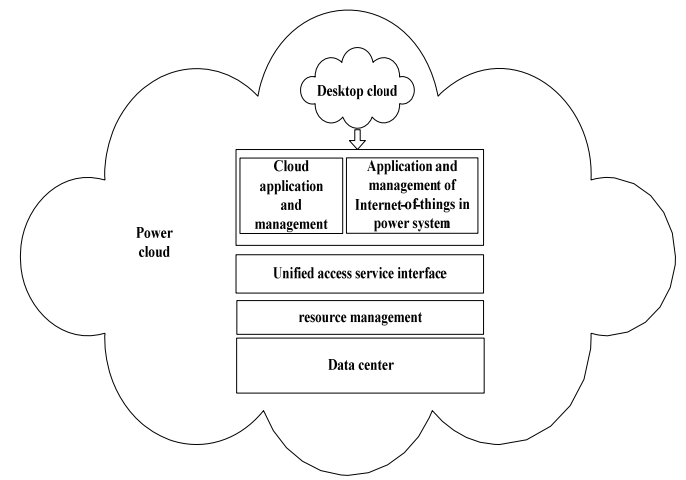

FIGURE IV. THE OVERALL STRUCTURE OF POWER CLOUD

\section{B. Contrast with Traditional Application Systems}

Compared with the traditional application systems, power cloud services integrated with heterogeneous application service systems have great advantages. The qualities of service are compared in Table I.

TABLE I. COMPARISON OF SERVICE QUALITIES BETWEEN POWER CLOUD AND TRADITIONAL APPLICATION SERVICE SYSTEM

\begin{tabular}{|c|c|c|}
\hline $\begin{array}{c}\text { quality of } \\
\text { service }\end{array}$ & $\begin{array}{c}\text { Traditional application } \\
\text { system }\end{array}$ & Power cloud service \\
\hline performance & $\begin{array}{l}\text { single function, small } \\
\text { scale, poor } \\
\text { compatibility, limited } \\
\text { resources }\end{array}$ & $\begin{array}{l}\text { multi service, large } \\
\text { scale, interactive } \\
\text { sharing, mass storage, } \\
\text { high speed, high } \\
\text { reliability }\end{array}$ \\
\hline $\begin{array}{l}\text { operation, } \\
\text { maintenance } \\
\text { and upgrade }\end{array}$ & $\begin{array}{l}\text { distributed Systems, } \\
\text { complex process of } \\
\text { operation, maintenance, } \\
\text { and upgrade, higher } \\
\text { costs of management }\end{array}$ & $\begin{array}{l}\text { unified maintenance and } \\
\text { upgrade, high } \\
\text { transparency, low } \\
\text { overhead }\end{array}$ \\
\hline $\begin{array}{l}\text { installation } \\
\text { and use }\end{array}$ & $\begin{array}{l}\text { one-time purchase, local } \\
\text { installation, local use }\end{array}$ & $\begin{array}{l}\text { dynamic expansion, } \\
\text { on-demand use, mobile } \\
\text { office }\end{array}$ \\
\hline $\begin{array}{l}\text { timeliness of } \\
\text { information }\end{array}$ & $\begin{array}{l}\text { historical data are used } \\
\text { for processing }\end{array}$ & $\begin{array}{l}\text { real-time and dynamic } \\
\text { information of power } \\
\text { grid can be mastered }\end{array}$ \\
\hline $\begin{array}{l}\text { economic and } \\
\text { environmental } \\
\text { benefits }\end{array}$ & $\begin{array}{l}\text { Need to put into a large } \\
\text { number of computers; } \\
\text { high power } \\
\text { consumption, low } \\
\text { utilization of hardware } \\
\text { resources, high costs }\end{array}$ & $\begin{array}{l}\text { Energy-saving and } \\
\text { environmentally } \\
\text { friendly; make full use } \\
\text { of idle resources; } \\
\text { manage data center in } \\
\text { background; high } \\
\text { economic efficiency }\end{array}$ \\
\hline
\end{tabular}

\section{CONCLUSIONS}

In this paper, the problems in the process of intelligent construction and development of power system are analyzed, the solution to which that integrates heterogeneous application service systems to build power cloud is proposed. Firstly, the basic concepts of cloud computing are introduced. Next, the architecture level of power cloud and the key technologies used in the implementation are analyzed. Then it focuses on the construction mechanism of power cloud which integrated with heterogeneous application service systems. Finally, the overall design of the structure of the power cloud is carried out. It is proved that, compared with traditional application service systems, power cloud has strong advantages: It can carry out real-time and dynamic analysis of power grid, take full use of existing computing resources, uniformly maintain and upgrade the systems and hardware facilities, so as to reduce the costs of operation and maintenance, and save energy expenditures; It can provide powerful computing and storage capacity, dynamic and scalable cloud services for power enterprises; Power cloud can realize mobile office for power enterprises as well. The application of cloud computing in power system is still in its infancy. Transferring the existing computing resources to the "cloud", the construction of various cloud application platforms for power system, and the security of cloud computing in power system are the key issues that need to be studied in the following stage.

\section{REFERENCES}

[1] TONG Weihua, "Development and trend of power system information in China,” J. Guangdong Science \&Technology, vol.21, no.3, pp. 69-70, 2012.

[2] GUO Junhua, WEN Fuquan, XUE Yusheng, “Cloud computing: implementing an essential computing platform for future power systems,” J. Automation of Electric Power Systems, vol.34, no.15, pp. 1-3, 2013.

[3] HE Yao, WANG Wenqing, XUE Fei, "Study of massive data mining based on cloud computing," J. Automation of Electric Power Systems, vol.34, no.15,pp. 15-18,2013.

[4] J.W. Rittinghouse, J.F.Ransome,”Cloud computing: implementation, management, and security,” Boca Raton, FL,USA :CRC Press , 2010.

[5] L.M. Vaquero, L. Rodero-Merino, J. Caceres, "A break in the clouds: towards a cloud definition," ACMSIGCOMM Computer Communication Review, vol.39, no.1, pp.50-55, 2009.

[6] M.D. Dikaiakos, D. Katsaros, P. Mehra, "Cloud computing: distributed Internet computing for IT and scientific research,” J. Internet Computing. IEEE, vol.16, no.5, 2009.

[7] Y. Jadeja, K. Modi, "Cloud computing - concepts, architecture and challenges,”C// IEEE Computing Electronics and Electrical Technologies (ICCEET), pp. 877-880, Kumaracoil, India,2012.

[8] SONG Yaqi, LIU Shuren, ZHU Yongli, "Cloud storage of power equipment state data sampled with high speed," J. Electric Power Automation Equipment, pp.150-153, vol.33, no.10, 2013.

[9] Y. Amanatullah, C. Lim, H. P. Ipung, Toward cloud computing reference architecture: Cloud service management perspective [C] // IEEE ICT for Smart Society (ICISS), 2013,Jakarta, Indonesia:1-4.

[10] FENG Wei, "The design and implementation of enterprise cloud management system's resource monitoring module,” Zhongshan: Zhongshan University,2012.

[11] WANG Yuhua, "Paas cloud management system design and development," Beijing: Beijing University of Posts and Telecommunications,2013. 